\title{
Multi-Attribute Optimization of the WEDM Process for Surface Characteristics and Productivity
}

\author{
Trung-Thanh NGUYEN, Khoa Dang NGUYEN*
}

\begin{abstract}
Wire-cut electrical discharge machining (WEDM) process is a proficient operation for the precise manufacturing of complex profiles of difficult-to-cut materials. The purpose of the current paper is to determine optimal processing inputs, including the WEDM current (CU), WEDM voltage (DV), pulse duration (Ton), and the speed of the wire electrode (WS) to decrease the depth of the recast layer $(D L)$ as well as the root mean square roughness (RMSR) and enhance the cutting speed (CS) of the WEDM operation. The radius basis function (RBF) approach is employed to develop the predictive models of technical responses. The non-dominated sorting particle swarm optimization (NSPSO) is applied to obtain the optimal values of processing inputs and WEDM performances measured. The findings revealed that the proposed $R B F$ models significantly contribute to the accurate prediction for the WEDM outputs. The optimal values of the CU, Ton, DV, and WS are $5.0 \mathrm{~A}, 6.0 \mu \mathrm{s}, 33.0 \mathrm{~V}$, and $4 \mathrm{~m} / \mathrm{min}$, respectively. The optimized values of the RMSR and DL are decreased by $60.98 \%$ and $15.55 \%$, respectively, while the CS is enhanced by $8.90 \%$. This work can be listed as an alternative solution for improving the surface characteristics and productivity of the WEDM process.
\end{abstract}

Keywords: cutting speed; optimization; parameters; root mean square roughness; the depth of the cast layer; WEDM

\section{INTRODUCTION}

The wire-cut electrical discharge machining (WEDM) is a proficient operation, which is widely applied in the precise manufacturing of complex profiles of difficult-tocut materials. Unfortunately, the various drawbacks, including the holes, cracks, craters, and high roughness are produced on the machined surface. Consequently, the selection of the proper factors to improve the machining performances of the WEDM process is an important demand.

Enhancing technical outputs for different WEDM operations have been attracted by former investigators. An attempt has been conducted to enhance the material removal rate $(M R R)$ and decrease the average surface roughness $(R a)$ for the WEDM operation of Inconel 706 [1]. The finding revealed that the pulse on duration $(P O D)$ of $105 \mu \mathrm{s}$, the pulse of duration $(P O F)$ of $27 \mu \mathrm{s}$, discharge voltage $(D V)$ of $32 \mathrm{~V}$, and the wire feed $(W F)$ of $4 \mathrm{~m} / \mathrm{min}$ were optimal values. The impacts of the $P O D, P O F$, and applied current $(A C)$ on the $M R R, R a$, and kerf width $(K W)$ of the 5754 aluminium alloy was explored by Shihab [2]. The author emphasized that $P O D$ was found to be the most significant in the responses measured. The response surface method (RSM) and heat transfer search algorithm (HTSA) were applied to select the optimal values of the $P O D, P O F$, and $A C$ for the WEDM of the NiTi alloy [3]. The obtained results indicated that the optimal outcomes of the $M R R$, hardness $(M H)$, and $R a$ were $1.49 \mathrm{~mm}^{3} / \mathrm{s}, 462.52$ $\mathrm{HVN}$, and $0.11 \mu \mathrm{m}$, respectively. A neuron network (NN) and wolf pack algorithm (WPA) were used to optimize the $P O D, A C$, water pressure $(W P)$, and feed rate $(F R)$ for minimizing the total machining time $\left(T_{\mathrm{P}}\right)$, manufacturing costs $\left(C_{\mathrm{P}}\right)$, and $R a$ [4]. The analysed outcomes revealed that the optimal values of the $T_{\mathrm{P}}, C_{\mathrm{P}}$, and $R a$ were $164.18 \mathrm{~min}$, 239.542 RMB, and $1.02 \mu \mathrm{m}$, respectively. Muralidharan et al. used the $R S M$ and desirability approach $(D A)$ to obtain the minimal values of the $P O D, P O F, D V$, and the weight ratio $\left(W_{\mathrm{t}}\right)$ for the WEDM of the aluminium matrix. The optimal outcomes of the $M R R$ and $R a$ were $0.077 \mathrm{~g} / \mathrm{min}$ and $3.62 \mu \mathrm{m}$, respectively.
The Kriging models were applied to render the predictive models of the cutting area rate $(\underline{C A R})$, kerf width $(K W)$, and $R a$ in terms of the POD, POF, $A C$, and $D V$ [6]. The feasible solutions obtained could be used to determine proper factors, which were satisfied with the optimization requirements. The Taguchi approach was used in conjunction with the NN to develop the model of the $M R R$, $R a, K W$, and cutting speed $(C S)$ for the WEDM of the Ti48Al alloy [7]. The accuracy of the developed models was confirmed using a set of experimental data. The authors stated that the 5-6-6-4 structure of the networks could provide the highest precision for prediction accuracy. Nawaz et al. found the optimal solutions of the $P O D, P O F$, $A C$, and $W S$ to improve the $M R R$ and decrease the $K W$ as well as $R a$ for a high-speed WEDM operation [8]. The obtained outcomes presented that the $A C$ was found to be the most affecting parameter on the $M R R$ and $R a$, while the $P O D$ is the most significant on the $K W$. The magneticassisted WEDM was applied to enhance the $M R R, R a$, and the depth of the recast layer $(D L)$ [9]. The non-dominated neighbour immune algorithm (NNIA) was used to find optimal outcomes. The results indicated that the improvements in the $M R R, R a$, and $D L$ were $22.37 \%$, $44.59 \%$, and $15.07 \%$, respectively. The reused wire technology was applied to decrease the $R a$ of the WEDM of Ti6Al4V alloy [10]. The author stated that the $R a$ was decreased by $2.65 \%$ with the aid of the new operation. The empirical models of the CA, $R a$, and $K W$ were developed in terms of the $P O D, P O F, D V, W P$, wire kind $(W K)$, and wire tension $(T W)$ for the WEDM of the hardened alloy [11]. The finding revealed that the $P O D$ is the most significant inputs, followed by the $W K$ and $P O F$, respectively. Similarly, the $R S M$ was applied to develop the predictive models of the $C S, R a$, and spark gap $(S G)$ of the WEDM of the $\mathrm{Al} / \mathrm{SiCp}-\mathrm{MMC}$ material [12]. The results generated by the $D A$ indicated that the $P O D$ of $0.75 \mu \mathrm{s}$, the $P O F$ of $16 \mu \mathrm{s}$, the $D V$ of $35 \mathrm{~V}$, the $A C$ of $120 \mathrm{~A}$, the $T W$ of $1200 \mathrm{~g}$, and the $W F$ of $10 \mathrm{~m} / \mathrm{min}$ were listed as the optimal solutions. The grey relation analysis (GRA) was applied to select the optimal parameters, including the $P O D, P O F$, $W F$, doping $(D P)$, and $W_{\mathrm{t}}$ for the magnesium matrix composite [13]. The optimal values of the $M R R$ and $R a$ 
were $14.9 \mathrm{~mm}^{3} / \mathrm{min}$ and $2.04 \mu \mathrm{m}$. The regression models of the cutting velocity $(\mathrm{CV})$ and $R a$ were proposed for the WEDM aluminum composite [14]. The optimum findings of the $C V$ and $R a$ were $8.12 \mathrm{~mm} / \mathrm{min}$ and $1.25 \mu \mathrm{m}$, respectively with the aid of the $D A$. The WEDM characteristics of the $16 \mathrm{MnCr} 5$ Alloy, including the $M R R$ and $R a$, were investigated by Saini et al. [15]. The author stated that the $P O D$ was the highest contributing factor for the technical responses.

In machining processes, surface quality is one of the most important customized requirements. The achievement of the desired surface quality is an urgent demand for the functionality of the machined part. The surface roughness value is a major indication of surface quality. The performances and production costs of the machined parts are strongly influenced by surface roughness, which influences the electrical as well as thermal conductivity, holding lubricant, friction, and geometric tolerances. A lower roughness leads to a reduction in the frictional coefficient, wear, corrosion, and adhesion [16, 17]. Therefore, a decrease in surface roughness ( $R a$ and/or $R M S R$ ) is necessary to achieve an eco-friendly machining process.

In this work, a parameter-based optimization of the WEDM operation for SS 304 has been considered to minimize the RMSR as well as the $D L$ and enhance the $C S$. The $R B F$ correlations were employed to depict the relations between the processing inputs and the measured parameters. An evolutionary algorithm namely NSPSO was applied to identify the global solution. The obtained result can be considered as an alternative solution to enhance surface properties and productivity for the WEDM operation. Moreover, the designed optimization method can become a useful approach for different machining operations to identify optimal outcomes.

\section{OPTIMIZATION APPROACH}

\subsection{Optimization Responses}

In the current paper, three WEDM performances measured, including the $R M S R, D L$, and $C S$, are improved with the aid of the optimization approach. The RMSR values are directly measured on the machined specimens.

The value of the $D L(\mu \mathrm{m})$ value is calculated as:

$$
D L=\frac{1}{20} \sum_{i=1}^{20} D L_{i}
$$

The cutting speed $(\mathrm{mm} / \mathrm{min})$ is computed as:

$$
C S=\frac{L_{\mathrm{m}}}{t_{\mathrm{m}}}
$$

where $L_{\mathrm{m}}$ - the machining length (mm), $T_{\mathrm{m}}$ - the machining time (min).

Table 1 WEDM processing inputs

\begin{tabular}{|c|c|c|c|c|}
\hline Table 1 WEDM processing inputs \\
\hline PEDM Current & $\mathrm{A}$ & 4.0 & 7.0 & 10.0 \\
\hline Pulse duration & $\mu \mathrm{s}$ & 1.0 & 4.0 & 7.0 \\
\hline WEDM voltage & $\mathrm{V}$ & 30.0 & 60.0 & 90.0 \\
\hline Wire speed & $\mathrm{m} / \mathrm{min}$ & 3.0 & 5.0 & 7.0 \\
\hline
\end{tabular}

In this work, key processing inputs considered are the WEDM current, WEDM voltage, pulse duration, and wire feed. Tab. 1 lists the lower and upper levels of each factor. The highest and lowest ranges are tested with the aid of the WEDM experiments to ensure machining capabilities.

\subsection{Optimization Procedure}

Fig. 1 presents an applied method for determining optimum factors. The proposed approach contains three primary steps.

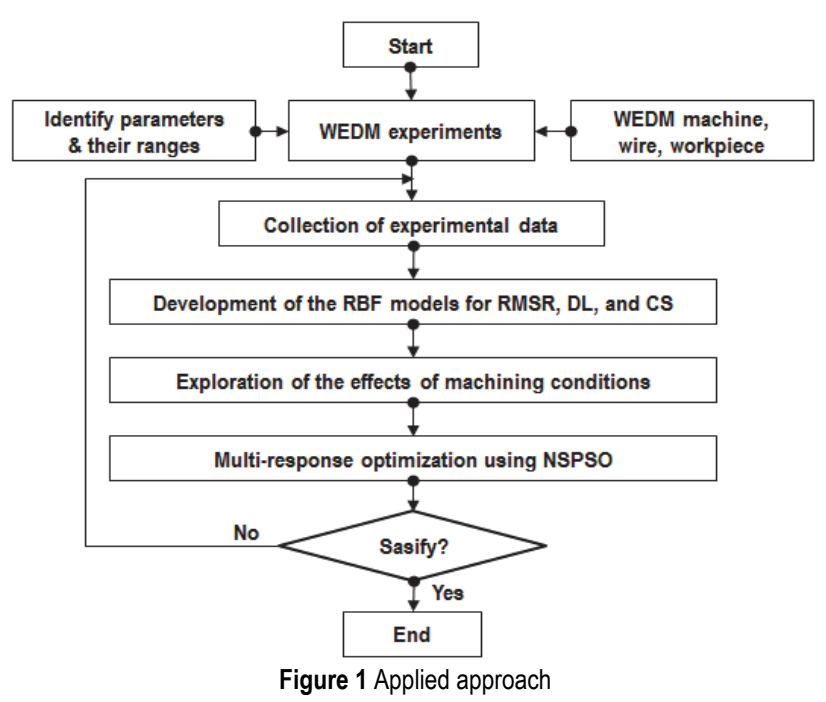

- The WEDM experiments are performed to collect the required data [18].

- The predictive correlations of the $R M S R, D L$, and $C S$ are constructed in terms of the processing inputs using the radius basis function approach.

The $R B F$ method is an alternative method to generate the interpolative model, which can be effectively employed to describe the non-linear data with wide levels. The radial units are employed in conjunction with the linear ones to present the experimental data. $R B F$ correlations show higher precision than the traditional models, such as response surface method or linear regression $[19,20]$. The $R B F$ model at the design point $(x)$ can be presented as:

$$
F(x)=\sum_{i=1}^{n} \lambda_{i} \phi\left(\left(x-x_{i}\right)+b x+c\right.
$$

where $\gamma$ - the positive constant, $\lambda_{i}, b$, and $c$ - the correlated factors.

These factors are calculated as:

$$
\left[\begin{array}{cc}
\phi & P \\
P^{\mathrm{T}} & 0
\end{array}\right]\left\{\begin{array}{l}
\lambda \\
a
\end{array}\right\}=\left\{\begin{array}{l}
G \\
0
\end{array}\right\}
$$

The $R B F$ forms can be expressed as:

$$
\varphi(r)=r
$$

Step 3: The NSPSO is employed to identify the optimal values of processing inputs and WEDM performances. The NSPSO is an effective optimization 
algorithm, which combines advantages of the Non-sorted dominated genetic algorithm (NSGA) and particle swarm optimization (PSO). The reliable solutions will be produced with the support of the NSPSO. The detail of the NSPSO is exhibited in the works of [21].The operating procedure of the NSPSO is depicted in Fig. 2.

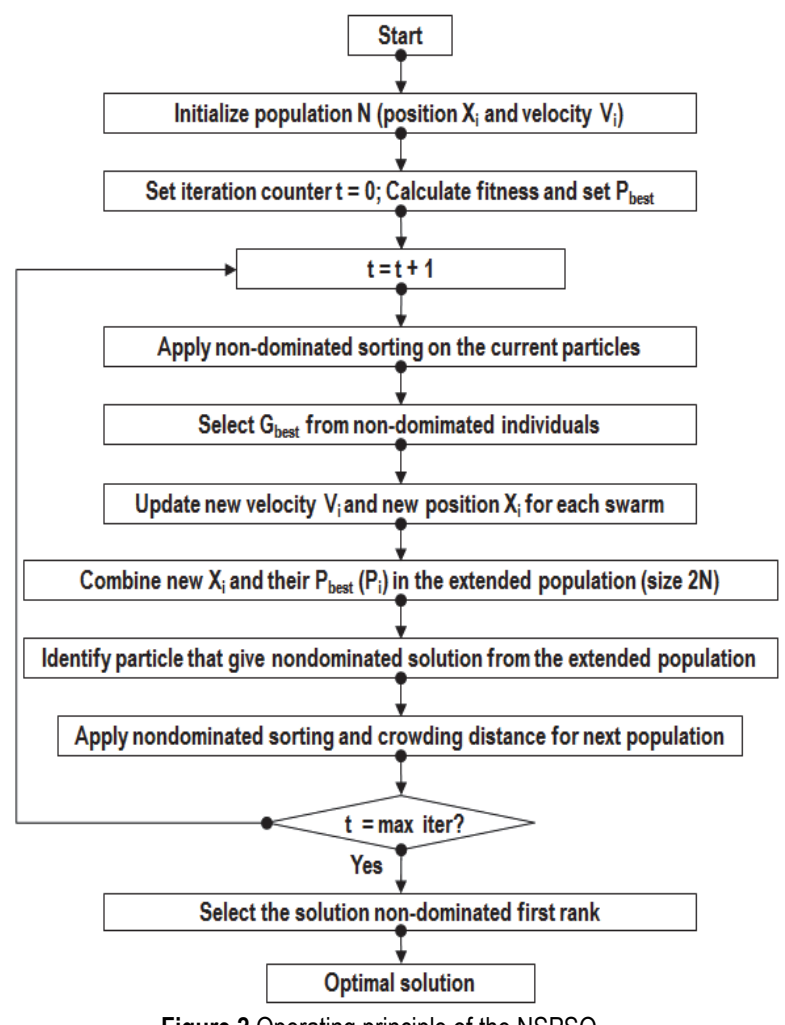

\section{WEDM EXPERIMENTS AND MEASUREMENTS}

All WEDM trials are conducted on the machine namely MTL-SFL70 to produce the machined specimens, as shown in Fig. 3. The machining path is directly programmed in the numerical controller of the machine. The dimensions of each workpiece are the length of 230 $\mathrm{mm}$, the width of $90 \mathrm{~mm}$, and the thickness of $8 \mathrm{~mm}$. The electrode wire using molybdenum material is employed for all experiments. After each trial, a new wire is changed to guarantee the machining precision. The machined length for each specimen is $30 \mathrm{~mm}$. The machined program is stopped when the desired length is completed. The machined specimen is cut from the workpiece to measure the WEDM performances. Moreover, each specimen is cleaned and polished to serve the measuring operation.

The roughness values are obtained with the aid of a portable machine labeled Mitutoyo SJ-301. Microscopy entitled Carl Zeiss 37081 is applied to investigate the value of the depth of the recast layer.

\section{RESULTS AND DISCUSSIONS \\ 4.1 Investigate the Model Adequacy}

The obtained data of the experimental WEDM operation are presented in Tab. 2. The representative values of the depth of the recast layer at different machining conditions are depicted in Fig. 4. The representative profiles of measured $R M S R$ at different machining conditions are shown in Fig. 5.

To evaluate the model adequacy, the coefficient of determination is assessed. The $R^{2}$ - values of the $R M S R$, $D L$, and $C S$ are 0.9924, 0.9874, and 0.9902, respectively, showing the acceptable agreement between predictive and actual data. The data are evenly distributed on the straight, presenting that the developed models are highly satisfactory, as shown in Fig. 6.

\subsection{Analysis of the Factor Effects}

The influences of the process parameters on the RMSR values are depicted in Fig. 7. In the WEDM process, a low roughness is a desirable indicator.

Fig. 7a revealed that higher roughness values are produced with an increased $C U$ and/or $D V$. When the low $C U$ and/or $D V$ are applied, the discharge energy is lower, which causes a low intensity of the WEDM spark. Less material is processed and vaporized. Moreover, the electrical spark is evenly distributed on the WEDM surface at the low $C U$ and/or $D V$, which generates a smoother surface and the RMSR value is decreased. A WEDM surface with small dimensions of the craters, cracks, and holes is observed.

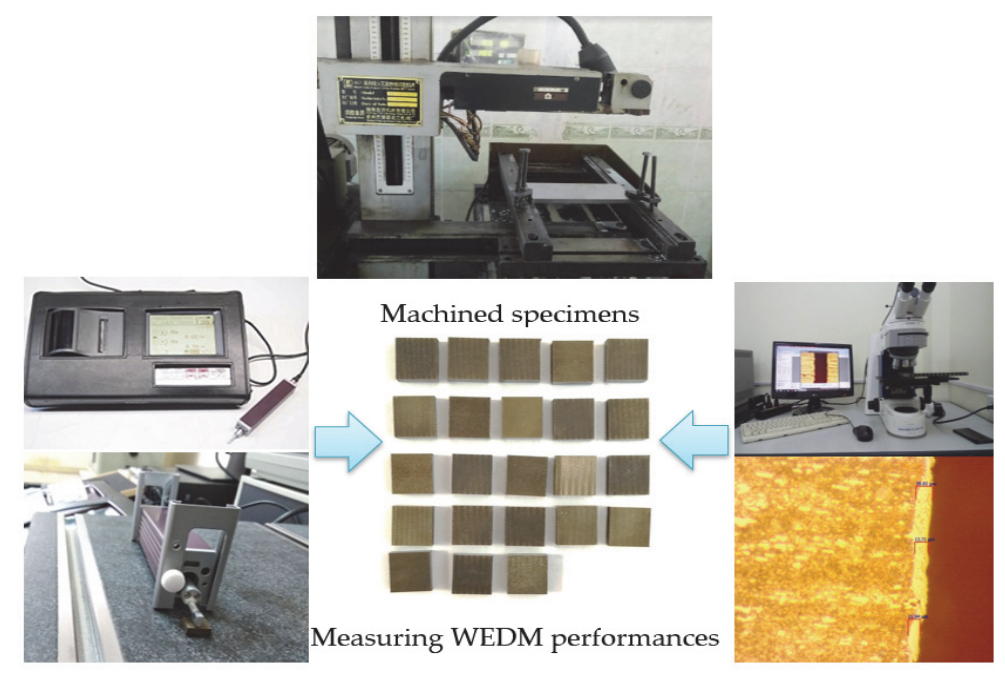

Figure 3 Experiment and measurement of the WEDM operation 
In contrast, an increased $C U$ and/or $D V$ lead to an increment in the discharge energy. Higher intensity of the electrical spark is produced, which significantly processes material. An increased material volume is melted and vaporized, which results in the formation of bigger holes, cracks, and craters. Therefore, higher roughness is generated.Fig. $7 \mathrm{~b}$ indicated that an increased RMSR is associated with an increment in the Ton and/or WS. After a maximal point, a further value of the Ton and/or $W S$ leads to a smoother surface. At a low value of the Ton and/or WS, a low electrical spark is obtained and evenly distributed on the machined surface. Less material is then processed and removed, which leads to a reduction in the roughness.
In contrast, an increased pulse duration results in increased intensity of discharge energy, and higher material volume is removed. Therefore, higher RMSR is obtained. Similarly, higher $W S$ causes increased discharge energy and intensive spark is produced. A higher amount of material is processed and removed, which causes a higher value of the RMSR. Fortunately, at the highest levels of the Ton and/or $W S$, the electrical spark is evenly distributed, leading to a reduction in the RMSR. A smoother surface is obtained at employing highest Ton and/or $W S$.

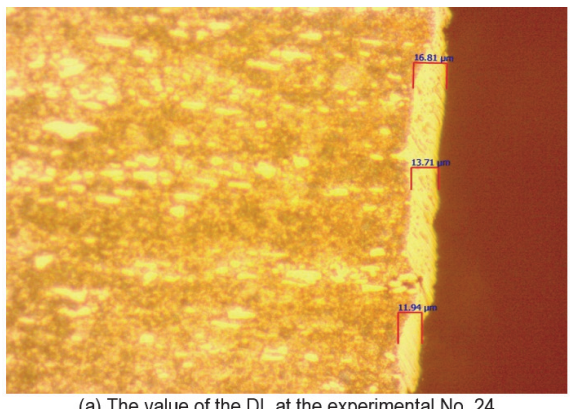

(a) The value of the $\mathrm{DL}$ at the experimental No. 24

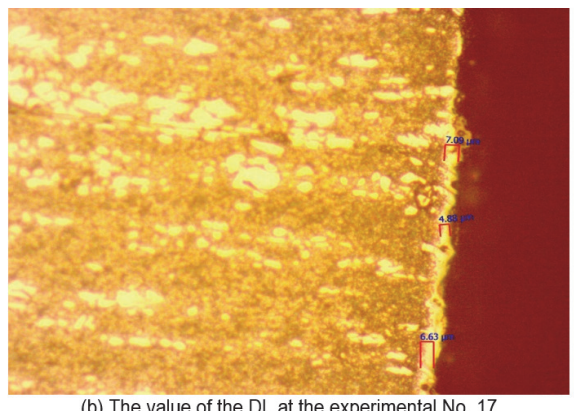

(b) The value of the $\mathrm{DL}$ at the experimental No. 17

Figure 4 The values of the depth of the recast layer at different inputs

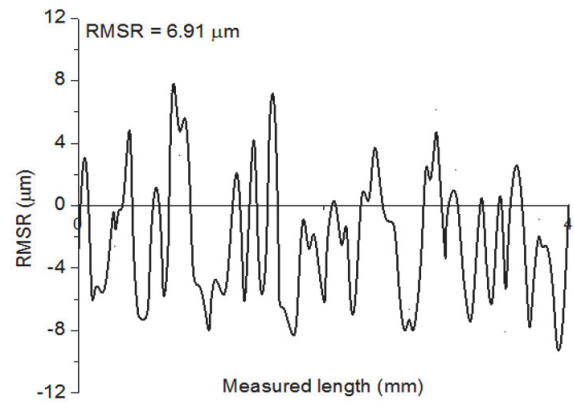

(a) The root mean square roughness at the experimental №. 14

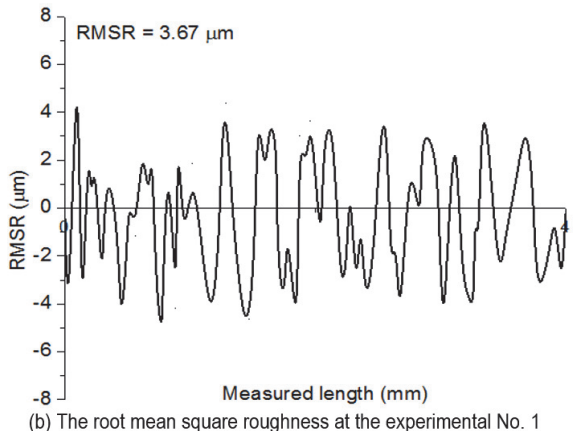

(b) The root mean square roughness at the experimental No. 1

Figure $\mathbf{5}$ The root mean square roughness at the different inputs

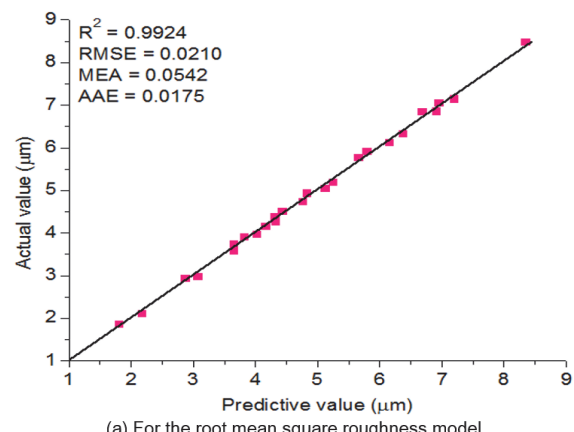

(a) For the root mean square roughness model

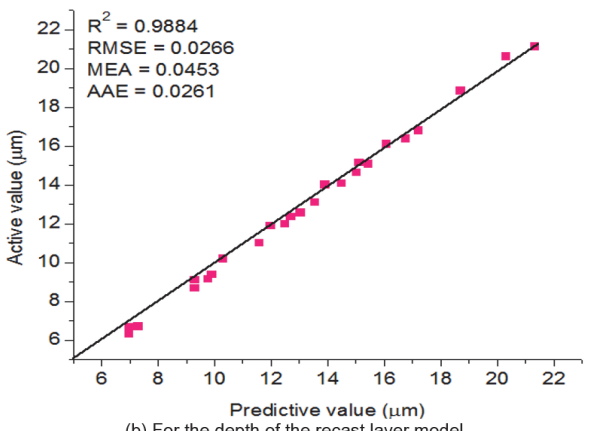

(b) For the depth of the recast layer model

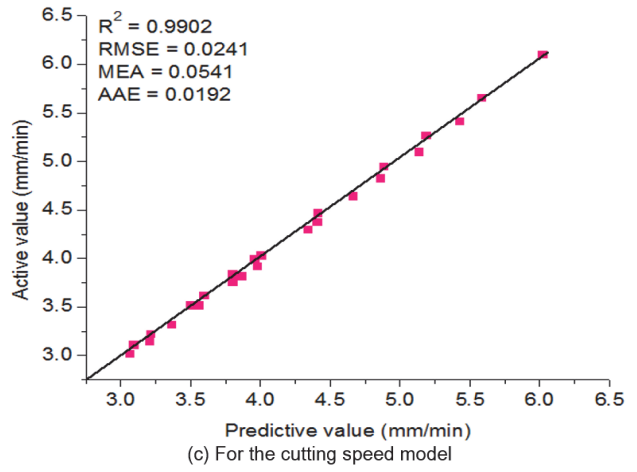

Figure 6 Investigation of the model adequacy 


\begin{tabular}{|c|c|c|c|c|c|c|c|c|c|c|c|c|c|c|c|}
\hline No. & $\begin{array}{l}C U \\
/ \mathrm{A}\end{array}$ & $\begin{array}{l}\text { Ton } \\
/ \mu \mathrm{s}\end{array}$ & $\begin{array}{l}D V \\
/ \mathrm{V}\end{array}$ & $\begin{array}{c}W S / \\
\mathrm{m} / \mathrm{min}\end{array}$ & $\begin{array}{c}\text { RMSR } \\
/ \mu \mathrm{m}\end{array}$ & $\begin{array}{c}D L \\
/ \mu \mathrm{m}\end{array}$ & $\begin{array}{c}C S \\
/ \mathrm{mm} / \mathrm{min}\end{array}$ & No. & $\begin{array}{l}C U \\
/ \mathrm{A}\end{array}$ & $\begin{array}{l}\text { Ton } \\
/ \mu \mathrm{s}\end{array}$ & $\begin{array}{l}D V \\
/ \mathrm{V}\end{array}$ & $\begin{array}{c}W S \\
/ \mathrm{m} / \mathrm{min}\end{array}$ & $\begin{array}{c}\text { RMSR } \\
/ \mu \mathrm{m}\end{array}$ & $\begin{array}{c}D L \\
/ \mu \mathrm{m}\end{array}$ & $\begin{array}{c}C S \\
/ \mathrm{mm} / \mathrm{min}\end{array}$ \\
\hline 1 & 4 & 1 & 60 & 5 & 3.67 & 8.68 & 3.07 & 14 & 4 & 4 & 90 & 5 & 6.91 & 14.92 & 4.30 \\
\hline 2 & 10 & 1 & 60 & 5 & 5.25 & 12.16 & 3.50 & 15 & 10 & 4 & 30 & 5 & 5.73 & 11.86 & 3.57 \\
\hline 3 & 4 & 7 & 60 & 5 & 4.32 & 16.83 & 5.09 & 16 & 10 & 4 & 90 & 5 & 8.51 & 18.64 & 4.62 \\
\hline 4 & 10 & 7 & 60 & 5 & 5.90 & 20.44 & 5.39 & 17 & 7 & 1 & 30 & 5 & 2.98 & 6.37 & 3.02 \\
\hline 5 & 7 & 4 & 30 & 3 & 2.13 & 6.17 & 3.30 & 18 & 7 & 1 & 90 & 5 & 5.73 & 12.99 & 3.96 \\
\hline 6 & 7 & 4 & 30 & 7 & 4.49 & 9.15 & 3.80 & 19 & 7 & 7 & 30 & 5 & 3.61 & 14.59 & 4.82 \\
\hline 7 & 7 & 4 & 90 & 3 & 4.89 & 13.69 & 4.37 & 20 & 7 & 7 & 90 & 5 & 6.39 & 21.19 & 6.06 \\
\hline 8 & 7 & 4 & 90 & 7 & 7.25 & 14.86 & 4.91 & 21 & 4 & 4 & 60 & 3 & 2.89 & 8.96 & 3.48 \\
\hline 9 & 7 & 1 & 60 & 3 & 1.79 & 6.08 & 3.16 & 22 & 4 & 4 & 60 & 7 & 5.12 & 10.91 & 3.93 \\
\hline 10 & 7 & 1 & 60 & 7 & 3.86 & 9.75 & 3.77 & 23 & 10 & 4 & 60 & 3 & 4.34 & 12.38 & 3.79 \\
\hline 11 & 7 & 7 & 60 & 3 & 2.14 & 15.88 & 5.21 & 24 & 10 & 4 & 60 & 7 & 6.84 & 14.58 & 4.36 \\
\hline 12 & 7 & 7 & 60 & 7 & 4.80 & 16.36 & 5.63 & 25 & 7 & 4 & 60 & 5 & 5.10 & 11.64 & 3.82 \\
\hline 13 & 4 & 4 & 30 & 5 & 4.16 & 8.48 & 3.17 & & 4 & 4 & 90 & 5 & 6.91 & 14.92 & 4.30 \\
\hline
\end{tabular}

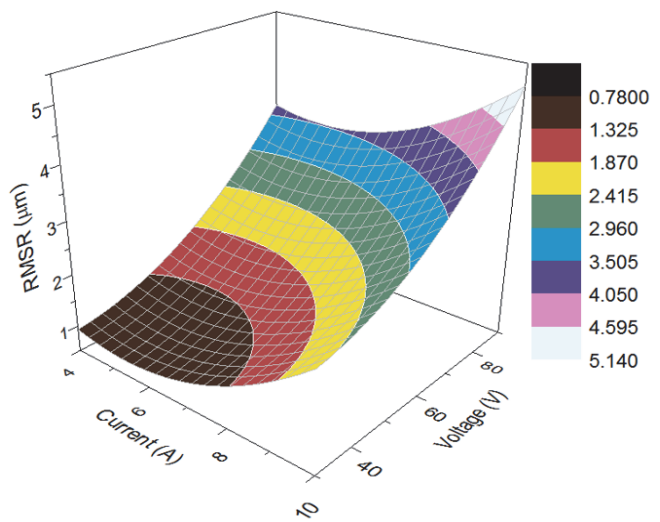

(a) RMSR versus CU and DV

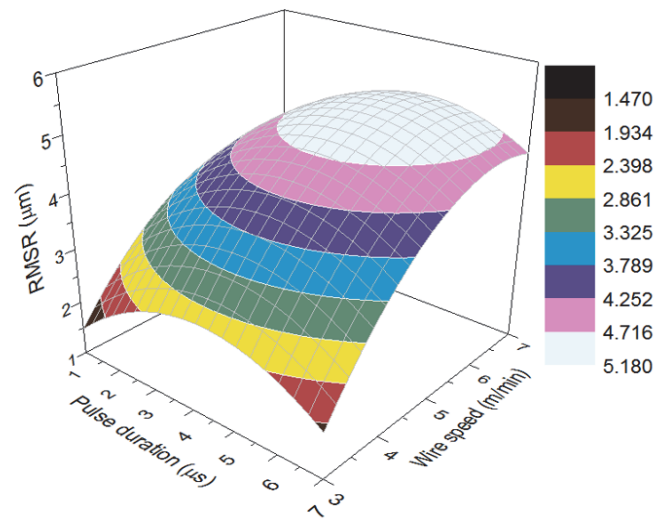

(b) RMSR versus Ton and WS

Figure 7 Interaction effects of processing conditions on the RMSR

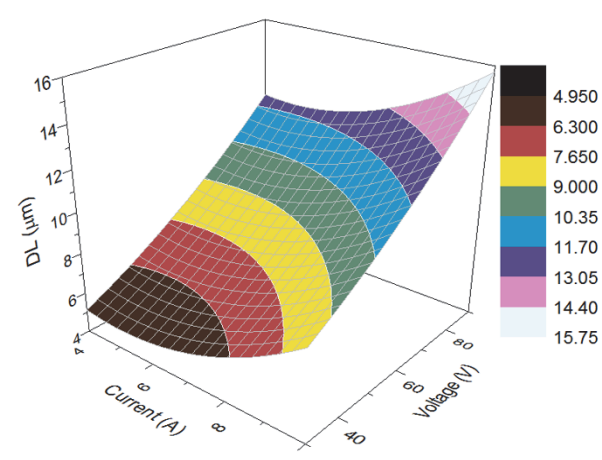

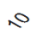

(a) DL versus $C U$ and DV

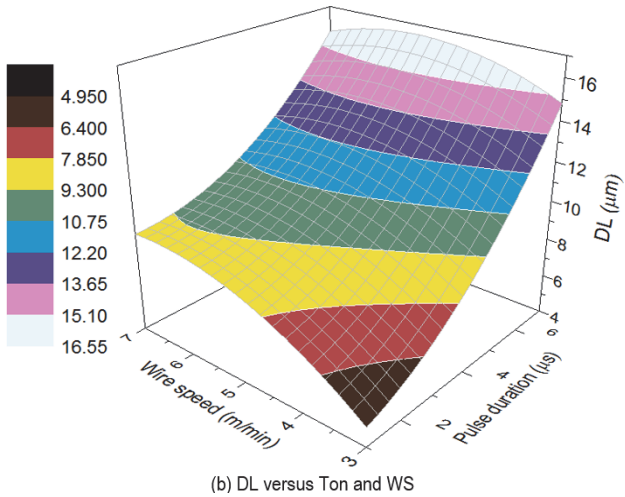

(b) $\mathrm{DL}$ versu
on the $D L$
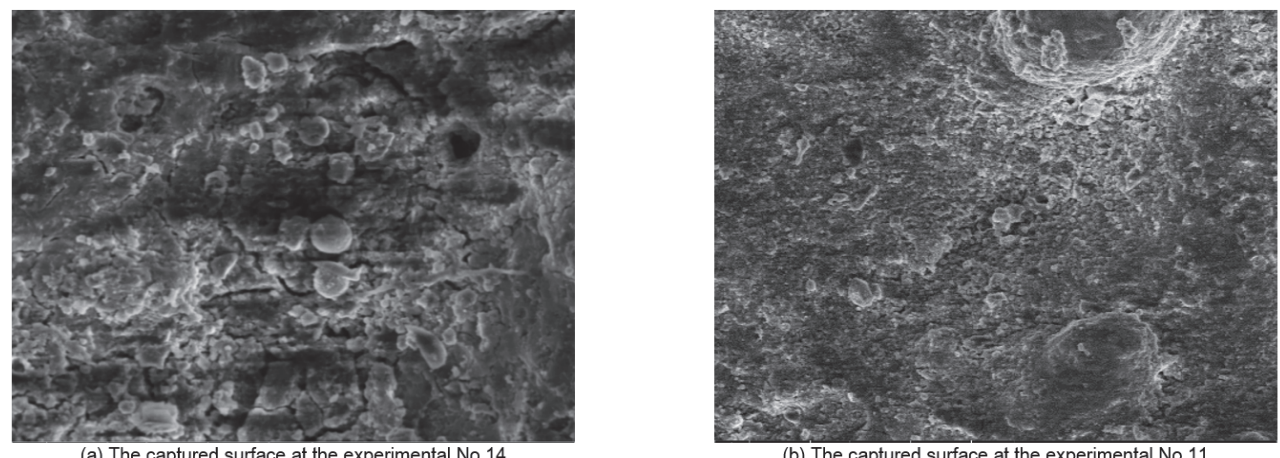

Figure 9 Captured surface at the various experiments

The effects of processing inputs on the $D L$ are shown in Fig. 8. In the WEDM process, a low depth is a desirable indicator.

Fig. 8a has revealed that an increased $D L$ is associated with an increment in the $C U$ and/or $D V$. At a low value of the $C U$ and/or $D V$, low electrical spark obtained causes less molten material. A small amount of material is released and solidified on the workpiece surface, which causes a low $D L$. When the $C U$ and/or $D V$ increase, increased discharge energy causes an increment in the volume of the molten material and machined zones. More material is processed and melted which causes thicker $D L$. 
Fig. $8 \mathrm{~b}$ indicated that an increased $D L$ is associated with an increment in the Ton and/or WS. When the Ton and/or WS increases, the higher intensity of the electrical spark is generated. Higher material volume is processed and evaporated, which increases the thickness of the solidified layer.

The captured surfaces with various processing inputs are presented in Fig. 9. A coarsen surface is observed at an increased $W S$, while the smooth one is obtained with the low condition.

Fig. 10 presents the influences of the processing inputs on the CL. In the WEDM process, a higher $C S$ is an important indicator to enhance productivity.

Fig. 10a revealed that an increased $C S$ is associated with an increment in the $C U$ and/or $D V$. At a lower value

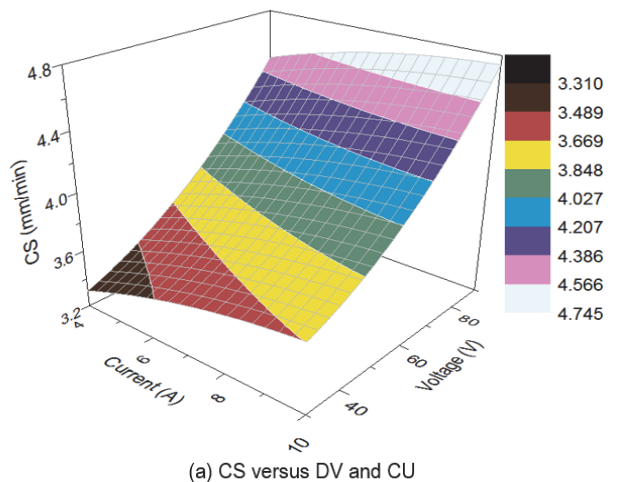

Figure 10 Interaction effects of processing conditions on the CS

The ANOVA analysis is used to analyze the contributions of the inputs $[20,21]$. Fig. 11a presents parametric contributions for the RMSR model. For single factor, the contributions of the $D V, W S, C U$, and Ton are $19.48 \%, 16.67 \%, 11.16 \%$ and $4.56 \%$. For the quadratic factors, the contributions of the $T o n^{2}, W S^{2}, C U^{2}$, and $D V^{2}$ are $13.86 \%, 13.69 \%, 9.41 \%$, and $7.91 \%$, respectively.

Fig. $11 \mathrm{~b}$ illustrates parametric contributions for the $D L$ model. For a single factor, the contributions of the Ton, $D V$, $C U$, and $W S$ are $25.17 \%, 20.26 \%, 10.87 \%$, and $6.36 \%$, respectively. For the quadratic factors, the contributions of the $T o n^{2}, C U^{2}, W S^{2}$, and $D V^{2}$ are $9.79 \%, 10.89 \%, 7.48 \%$, and $3.49 \%$, respectively.

Parametric contributions for the $C S$ model are depicted in Fig. 11c. The contributions of the Ton, $D V, W S$, and $C U$ are $32.51 \%, 18.14 \%, 8.53 \%$, and $6.08 \%$, respectively. The contributions of the $T o n^{2}, D V^{2}, W S^{2}$, and $C U^{2}$ are $16.50 \%$, $4.95 \%, 4.13 \%$, and $1.80 \%$, respectively. of $C U$ and/or $D V$, low intensity of discharge energy and electrical spark is generated. Less material is molten and evaporated; hence, the value of the $C S$ is reduced. In contrast, a higher intensity of discharge energy is produced when the $C U$ and/or $D V$ increases. More material volume is processed and higher $C S$ is obtained.

Fig. 10b indicated that an increased $C S$ is associated with an increment in the Ton and/or WS. When the Ton and/or $W S$ increases, an increment in the electrical spark is obtained. As a result, more material volume is vaporized, which causes higher $C S$ value. Moreover, the debris is effectively flushed out at high value of the wire speed, contributing to faster cutting speed.

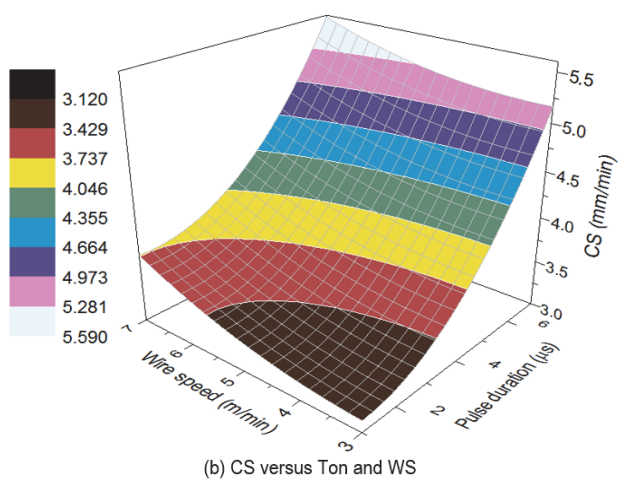

\subsection{Optimal Results}

The optimization factors are determined using the developed $R B F$ models and PSO algorithm. The values of the operating parameters, including the maximum iterations, number of particles, inertia, global increment, particle increment, maximum velocity are 50, 20, 0.9, 0.9, 0.9 , and 0.2 , respectively.

Fig. 12 depicts the graphical relations between the WEDM responses for showing optimization solutions. It was found that the WEDM responses have a contradictory trend. An increased $C S$ leads to a reduction in the surface quality or an increase in the RMSR and $D L$. The point labeled No. 522 is selected as a proper solution, which satisfies optimization issues.

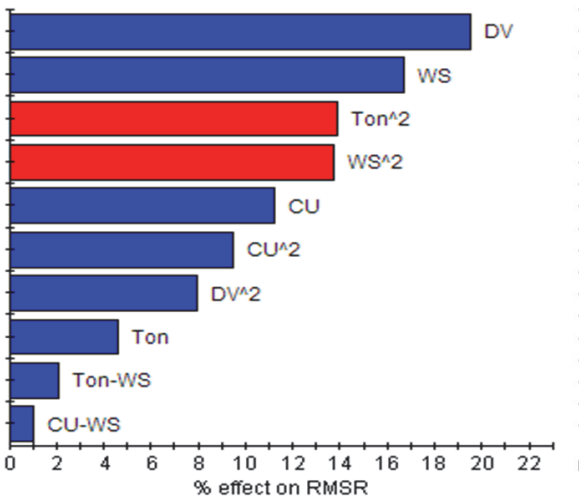

(a) The parametric contributions for the RMSR

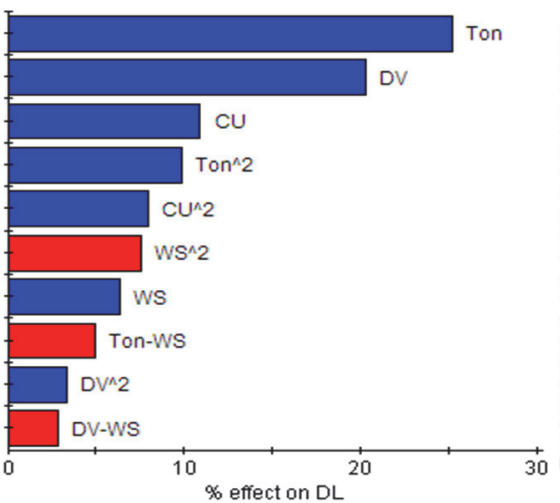

(b) The parametric contributions for the $D L$

Figure 11 Parameters' contributions for WEDM responses

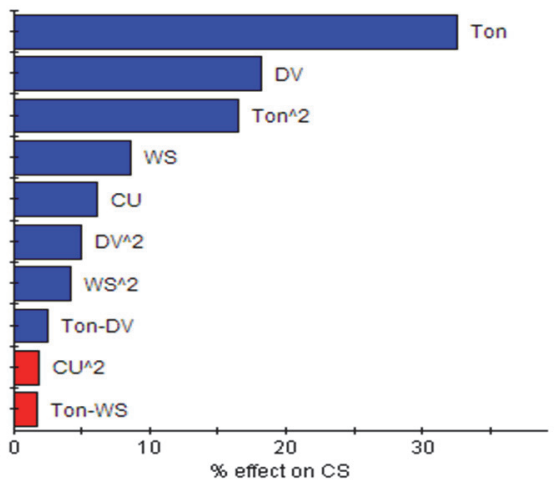

(c) The parametric contributions for the CS 
The optimal WEDM inputs and outputs are presented in Tab. 3. The CU of $5.0 \mathrm{~A}$, DV of $33 \mathrm{~V}$, Ton of $6.0 \mu \mathrm{s}$, and WS of $4.0 \mathrm{~m} / \mathrm{min}$ are optima. As a result, the reductions of the RMSR and DL are $60.98 \%$ and $15.55 \%$, respectively, while the CS is improved by $8.90 \%$ in comparison with initial values
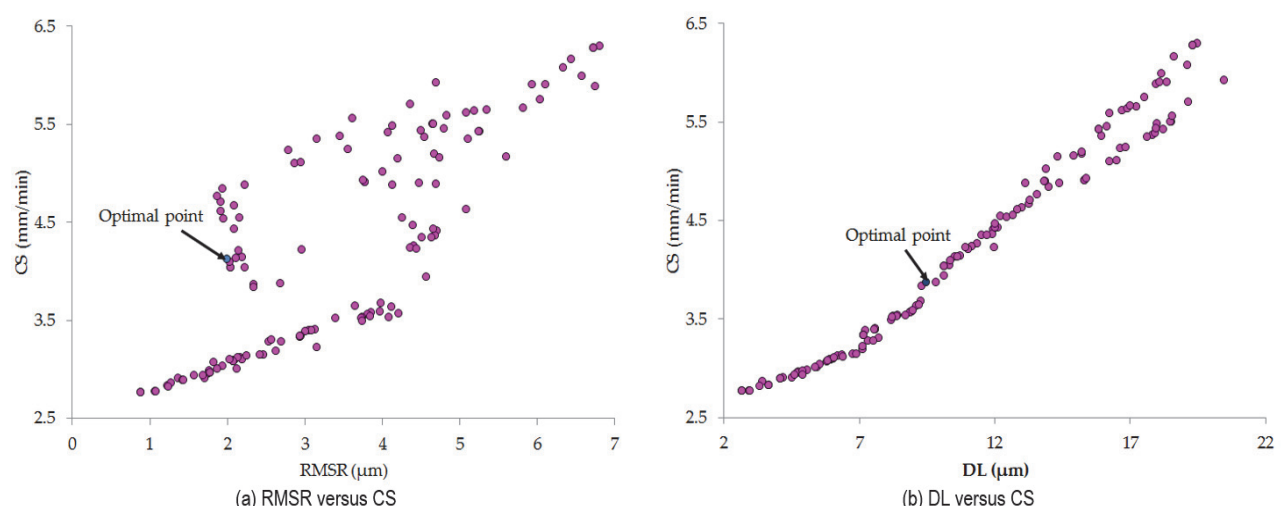

Figure 12 Pareto fronts produced by NSPSO

Table 3 Optimization results produced by NSPSO

\begin{tabular}{|c|c|c|c|c|c|c|c|}
\hline \multirow{2}{*}{ Approach } & \multicolumn{4}{|c|}{ Optimum parameters } & \multicolumn{3}{|c|}{ Optimum responses } \\
\hline & $C U / \mathrm{A}$ & $D V / \mathrm{V}$ & $\begin{array}{c}\text { Ton / } \\
\mu \mathrm{s}\end{array}$ & $\begin{array}{c}W S / \\
\mathrm{m} / \mathrm{min}\end{array}$ & $R M S R / \mu \mathrm{m}$ & $D L / \mu \mathrm{m}$ & $C S / \mathrm{mm} / \mathrm{min}$ \\
\hline Values used & 7.0 & 60.0 & 4.0 & 5.0 & 5.10 & 11.64 & 3.82 \\
\hline NSPSO & 5.0 & 33.0 & 6.0 & 4.0 & 1.99 & 9.83 & 4.16 \\
\hline Improvement / \% & & & & & -60.98 & -15.55 & 8.90 \\
\hline
\end{tabular}

\section{CONCLUSIONS}

The current research addressed the WEDM input based-optimization of SS304 that decreases the root mean square roughness as well as the depth of the recast layer and improves the cutting speed. The nonlinear correlations of the machining targets were developed using $R B F$ models. The PSO was employed to obtain optimal outcomes of processing inputs and technical performances. The findings can be summarized as follows:

1 . The $R B F$ correlations of the WEDM characteristics have shown a higher precision for prediction purposes. The modeling technique is employed to depict complex data instead of traditional ones. These correlations may be satisfactorily applied for the prediction of the objective's values.

2. The optimal factor settings obtained by NSPSO of the $C U$, Ton, $D V$, and $W S$ are $5.0 \mathrm{~A}, 6.0 \mu \mathrm{s}, 33.0 \mathrm{~V}$, and 4 $\mathrm{m} / \mathrm{min}$, respectively. As compared to random values, the RMSR and $D L$ are decreased by $60.89 \%$ and $15.55 \%$, respectively. The $C S$ value is improved by $8.90 \%$.

3. The developed approach could be employed to solve the relations between the contradictory responses. The proposed optimization approach effectively supports the WEDM operator to select the optimum process parameters. 4. An integrative approach comprising the $R B F$ model and PSO effectively supports the optimizing WEDM operation and generates reliable results, as compared to the human trials or experience.

5. This work addressed the three machining responses including the $R M S R, D L$, and $C S$ that were considered as objective outputs. Other responses such as the tool wear rate and energy used should be studied in order to holistically optimize the WEDM process. Moreover, additional parameters including the residual stress and machining costs will be analyzed in future works.

\section{Acknowledgment}

This research is funded by the Vietnam National Foundation for Science and Technology Development (NAFOSTED) under grant number 107.04-2020.02.

\section{REFERENCES}

[1] Sharma, P., Chakradhar, D., \& S., N. (2018). Analysis and Optimization of WEDM Performance Characteristics of Inconel 706 for Aerospace Application. Silicon, 10, 921-930. https://doi.org/10.1007/s12633-017-9549-6

[2] Shihab, S. K. (2018). Optimization of WEDM Process Parameters for Machining of Friction-Stir-Welded 5754 Aluminum Alloy Using Box-Behnken Design of RSM. Arab. J. Sci. Eng. 43, 5017-5027. https://doi.org/10.1007/s13369-018-3238-7

[3] Chaudhari, R., Vora, J. J., Prabu, S. S. M. et al. (2019). Pareto optimization of WEDM process parameters for machining a NiTi shape memory alloy using a combined approach of RSM and heat transfer search algorithm. $A d v$. Manuf. https://doi.org/10.1007/s40436-019-00267-0

[4] Ming, W., Hou, J., Zhang, Z. et al. (2016). Integrated ANNLWPA for cutting parameter optimization in WEDM. $A d v$. Manuf. Technol. 84, 1277-1294. https://doi.org/10.1007/s00170-015-7777-8

[5] Muralidharan, N., Chockalingam, K., Parameshwaran, R. et al. (2020). Optimization of CNC-WEDM Parameters for AA2024/ZrB2 in situ Stir Cast Composites Using Response Surface Methodology with Desirability Function Technique. Arab. J. Sci. Eng. 45, 5563-5579. https://doi.org/10.1007/s13369-020-04490-x

[6] Nguyen, T. \& Duong, Q. (2019). Optimization of WEDM process of mould material using Kriging model to improve technological performances. Sādhanā, 44, 154. https://doi.org/10.1007/s12046-019-1133-x

[7] Yusoff, Y., Zain, A.M., Amrin, A. et al. (2019). Orthogonal based ANN and multiGA for optimization on WEDM of Ti48Al intermetallic alloys. Artif. Intell. Rev. 52, 671.706 https://doi.org/10.1007/s10462-017-9602-2 
[8] Nawaz, Y., Maqsood, S., Naeem, K. et al. (2020). Parametric optimization of material removal rate, surface roughness, and kerf width in high-speed wire electric discharge machining (HS-WEDM) of DC53 die steel. Int. J.Adv. Mamuf. Technol, 107, 3231-3245. https://doi.org/10.1007/s00170-020-05175-3

[9] Zhang, G., Zhang, Y., Chen, Z. et al. (2018). Magneticassisted method and multi-objective optimization for improving the machining characteristics of WEDM in trim cutting magnetic material.Int. J. Adv. Mamuf. Technol., 98,14711488. https://doi.org/10.1007/s00170-018-2184-6

[10] Devarasiddappa, D., Chandrasekaran, M., \& Arunachalam, R. (2020). Experimental investigation and parametric optimization for minimizing surface roughness during WEDM of Ti6Al4V alloy using modified TLBO algorithm. J. Braz. Soc. Mech. Sci. Eng., 42, 128. https://doi.org/10.1007/s40430-020-2224-7

[11] Tahir, W. \& Jahanzaib, M. (2019). Multi-objective optimization of WEDM using cold treated brass wire for HSLA hardened steel. J. Braz. Soc. Mech. Sci. Eng., 41, 525. https://doi.org/10.1007/s40430-019-2028-9

[12] Kumar, H., Manna, A., \& Kumar, R. (2018). Modeling and desirability approach-based multi-response optimization of WEDM parameters in machining of aluminum metal matrix composite. J Braz. Soc. Mech. Sci. Eng., 40, 458. https://doi.org/10.1007/s40430-018-1368-1

[13] Kavimani, V., Prakash, K. S., Thankachan, T. et al. (2020). WEDM Parameter Optimization for Silicon@rGO/Magneisum Composite Using Taguchi Based GRA Coupled PCA. Silicon, 12, 1161-1175. https://doi.org/10.1007/s12633-019-00205-6

[14] Garg, S. K., Manna, A., \& Jain, A. (2014). An Investigation on Machinability of $\mathrm{Al} / 10 \% \mathrm{ZrO} 2(\mathrm{P})$-Metal Matrix Composite by WEDM and Parametric Optimization Using Desirability Function Approach. Arab. J. Sci. Eng., 39, 32513270. https://doi.org/10.1007/s13369-013-0941-2

[15] Saini, T., Goyal, K., \& Bhandari, D. (2019). Multi-response optimization of WEDM parameters on machining $16 \mathrm{MnCr} 5$ alloy steel using Taguchi technique. Multiscale and Multidiscip. Model. Exp. and Des., 2, 35-47. https://doi.org/10.1007/s41939-018-0027-7

[16] Maruda, R. W., Krolczyk, G. M., Wojciechowski, S. et al. (2018). Effects of extreme pressure and anti-wear additives on surface topography and tool wear during MQCL turning of AISI 1045 steel. Journal of Mechanical Science and Technology, 32(2), 1585-1591. https://doi.org/10.1007/s12206-018-0313-7

[17] Nieslony, P., et al. (2018). Surface quality and topographic inspection of variable compliance part after precise turning. Applied Surface Science, 434, 91-101. https://doi.org/10.1016/j.apsusc.2017.10.158

[18] Zhang, Y., Luo, X., Zhu, C. Lu, W., \& Wang, X. (2019). Optimization of Gait Parameters for Energy Efficiency Improvement of Farmland Robot Based on Orthogonal Experiment Design. Technical gazette, 26(3), 703-709. https://doi.org/10.17559/TV-20190104090943

[19] Nguyen, T. T. \& Cao, L. H. (2020). Optimization of the Burnishing Process for Energy Responses and Surface Properties. International Journal of Precision Engineering and Manufacturing. https://doi.org/10.1007/s12541-020-00326-8

[20] Nguyen, T. T., Cao. L. H., Nguyen, T. A., \& Dang, X. P. (2019). Multi-response optimization of the roller burnishing process in terms of energy consumption and product quality. Journal of Cleaner Production, 245(1), 119328. https://doi.org/10.1016/j.jclepro.2019.119328

[21] Yang, L. (2008). A fast and elitist multi-objective particle swarm algorithm: NSPSO. IEEE International Conference on Granular Computing, Hangzhou, 470-475. https://doi.org/10.1109/GRC.2008.4664711

\section{Contact information:}

Trung-Thanh NGUYEN, PhD

Department of Manufacturing Technology,

Le Quy Don Technical University, 236 Hoang Quoc Viet,

Ha Noi 100000, Viet Nam

Email: trungthanhk21@mta.edu.vn

\section{Khoa Dang NGUYEN, PhD}

(Corresponding author)

Faculty of Electrical and Electronic Engineering,

Phenikaa University,

Yen Nghia, Ha Đong,Hanoi 12116, Vietnam

Phenikaa Research and Technology Institute (PRATI), A\&A Green Phoenix Group JSC, No. 167 Hoang Ngan, Trung Hoa, Cau Giay, Hanoi 11313, Vietnam Email: khoa.nguyendang@phenikaa-uni.edu.vn 